\title{
Behavioral Mechanisms in HIV Epidemiology and Prevention: Past, Present, and Future Roles
}

\author{
Jeffrey B. Bingenheimer and Arline T. Geronimus
}

\begin{abstract}
In the 1980s, behavioral variations across geographically and socially defined populations were the central focus of AIDS research, and behavior change was seen as the primary means of controlling HIV epidemics. Today, biological mechanisms - especially other sexually transmitted infections, antiretroviral therapy, and male circumcision - predominate in HIV epidemiology and prevention. We describe several reasons for this shift in emphasis. Although the shift is understandable, we argue for a sustained focus on behavioral mechanisms in HIV research in order to realize the theoretical promise of interventions targeting the biological aspects of HIV risk. We also provide evidence to suggest that large reductions in HIV prevalence may be accomplished by small changes in behavior. Moreover, we contend that behavioral mechanisms will find their proper place in HIV epidemiology and prevention only when investigators adopt a conceptual model that treats prevalence as a determinant as well as an outcome of behavior and that explicitly recognizes the dynamic interdependence between behavior and other epidemiological and demographic parameters. (Studies in Family Planning 2009; 40[3]: 187-204)
\end{abstract}

Among the most striking features of the global spread of HIV is its heterogeneity across geographically and socially defined populations. According to recent estimates of the Joint United Nations Programme on HIV / AIDS (UNAIDS 2008), HIV prevalence among adults varies at the regional level by a factor of 50 , from 0.1 percent in East Asia to 5.0 percent in sub-Saharan Africa. Considerable variation can be found also within regions. Adult HIV prevalence exceeds 20 percent in the Southern African countries of Botswana, Lesotho, and Swaziland, for example, but remains below 5 percent in most West African countries (UNAIDS 2008). These geographical variations cannot be explained by chronological differences in when HIV was first introduced into regional or national populations (Caraël and Holmes 2001).

The spread of HIV has been characterized also by sharp variations between socially defined groups liv-

Jeffrey B. Bingenheimer is NICHD Postdoctoral Fellow, Population Research Institute, Pennsylvania State University, 601 Oswald Tower, University Park, PA 16802. E-mail: bartbing@pop.psu.edu. Arline T. Geronimus is Professor, Department of Health Behavior and Health Education, and Research Professor, Population Studies Center, University of Michigan, Ann Arbor, MI. ing in close proximity. In the United States, HIV spread aggressively among injection-drug users and men who have sex with men in several cities between 1978 and 1983, with prevalence surpassing 80 percent in some cohorts (Jaffe et al. 1985; Hessol et al. 1989; Des Jarlais et al. 1991; Hoover et al. 1991; van Griensven et al. 1993), yet it scarcely gained a foothold among other residents of the same cities during that period. More recently, HIV infections and AIDS diagnoses in the United States have become concentrated among racial and ethnic minority groups (Smith et al. 2000; Karon et al. 2001; McQuillan et al. 2006; Morris et al. 2006). According to surveillance estimates (CDC 2006), the rate of AIDS diagnosis among African Americans now exceeds ten times that among nonHispanic whites. Meanwhile, a survey conducted in several American cities during the late 1990s revealed an HIV-prevalence level of 29 percent among African American men who have sex with men (Catania et al. 2001).

Understanding the processes that generate these wide variations is of great interest to scientists and policymakers. In this study, we consider the changing role of behavioral mechanisms in epidemiological explanations for variations in the spread of HIV across geographically and socially defined populations and in strategies for controlling HIV epidemics. ${ }^{1}$ The discussion below is organized in part as a historical narrative. 
In the 1980s, behavioral variations within and between populations were the central focus of AIDS research, and behavior change was seen as the primary if not the sole means of controlling HIV epidemics. Today, biological mechanisms - especially other sexually transmitted infections, antiretroviral therapy, and male circumcision-predominate in HIV epidemiology and prevention efforts. ${ }^{2}$ We consider reasons for this shifting emphasis, but argue for a sustained focus on behavioral mechanisms in HIV research. We also advocate for a revised formulation of HIV epidemiology's central conceptual model to recognize explicitly the dynamism of human behavior and the interdependence between behavioral and biological determinants of risk.

\section{HIV Epidemiology's Conceptual Framework}

For almost three decades, the conceptual framework that has guided epidemiological thinking and research about the spread of HIV has contributed to a division in focus between behavior and biology. It has posited three categories of proximate determinants: (1) the behavioral mechanisms through which exposures occur, (2) the biological mechanisms that govern the probability that an exposure results in an infection, and (3) the factors (demographic and biomedical) that shape the duration of infectiousness. The collective determinants in these three categories are sometimes denoted as $c, \beta$, and $D$, respectively. The notion that they operate in concert to determine the spread of HIV is embodied in mathematical models ${ }^{3}$ and simplified in the expression $R_{0}=c \beta D$, where $c$ is defined as the number of new sexual partnerships per person per unit of time, $\beta$ is the probability that HIV is transmitted during sex between a susceptible and an infected partner, and $D$ is the length of time a newly infected person is expected to remain alive, sexually active, and infectious. If infected people die at rates $k$ and $\mu$ from HIV infection and all other causes, respectively, but remain sexually active and infectious until they die, then $R_{0}=c \beta /(\mu+k)$. Specified in this way, $R_{0}$ can be interpreted as the expected number of secondary infections caused by introducing one infected person into a large susceptible population, and HIV prevalence is predicted to converge over time toward an equilibrium level of $P^{*}=1-1 / R_{0}$.

In this conceptual framework, however, the function of the equation $R_{0}=c \beta D$ is heuristic rather than predictive. The parameters $c, \beta$, and $D$ refer loosely to collections of influences, and $R_{0}$ refers in a broad way to the severity of the HIV epidemic in a given population. The majority of HIV epidemiologists never work directly with mathematical models, but instead rely upon the formula $R_{0}=c \beta D$ mainly as a form of shorthand for the largely intuitive conceptual framework.

The conceptual framework provides the central organizing principle for HIV epidemiology and guides research and prevention efforts alike (Brunham 2005). By and large it encourages HIV epidemiologists to work backward from outcomes at the individual and population levels. It also promotes a compartmentalization of effort between "behavior" and "biology" camps. Some investigators focus on identifying routes of transmission and characterizing patterns in the corresponding behavioral mechanisms, represented by $c$. Others turn their attention to the search for biological mechanisms that influence susceptibility and infectiousness, summarized by $\beta$. In theory, the duration of infectiousness could also play a role, but mechanisms in this category have received little attention from HIV epidemiologists (except insofar as mechanisms such as antiretroviral therapy that influence $\beta$ are thought also to have countervailing influences on $D$ ).

HIV epidemiologists take for granted that variations in these proximate mechanisms may, in turn, be attributable to social factors. According to this perspective, "upstream" variables may contribute to the spread of HIV, but they do so only indirectly, through their effects on the proximate determinants (Aral and Holmes 1999; Boerma and Weir 2005; Hayes and Weiss 2006). That $c, \beta$, and $D$ (or their more complex generalizations) are seldom written explicitly as functions of social variables therefore reflects uncertainty about which social variables influence which proximate mechanisms in which populations, as well as epidemiologists' greater comfort in dealing with biological than with social factors. This uncertainty reinforces the strategy of working backward. The assumption is implicit that research on more remote influences will be fruitful only if it is adequately informed by a detailed understanding of the intervening proximate mechanisms, be they behavioral, biological, or demographic.

\section{Early Prominence of Behavioral Mechanisms}

Epidemiological research on the condition now known as AIDS began in 1981 when the first cases were reported to the Centers for Disease Control (CDC). Because the retrovirus now known as HIV had not yet been identified, epidemiological investigations were directed at narrowing the search for the cause(s) of the unusual cancers and infectious diseases appearing among gay and bisexual men and injection-drug users in several American cities. Clinical case studies provided valuable insights, particu- 
larly regarding the underlying commonality of cellular immune dysfunction. Equally important, however, were individual- and group-level behavioral comparisons.

All of the early surveillance reports (CDC 1981a, 1981b, and 1981c) and clinical case studies (Gottlieb et al. 1981; Masur et al. 1981; Siegal et al. 1981) noted that the overwhelming majority of identified AIDS cases had occurred among men who characterized themselves as homosexuals. This observation provided the primary basis for speculation about etiological agents and behavioral mechanisms (Durack 1981; Fauci 1982; Haverkos and Curran 1982). The leading hypotheses involved behaviors presumed to differentiate male homosexuals in New York and California from the rest of the population of the United States at that time-specifically, recreational use of nitrite inhalants and sexual practices (especially penileanal intercourse with multiple partners) through which exposure to the unknown cause(s) of this immune deficiency was presumed to occur.

Over the next several months, identification of AIDS cases among heterosexuals, injection-drug users, and hemophiliacs and other transfusion recipients pointed strongly toward a new, blood-borne, sexually transmissible agent (Jaffe et al. 1983a). That agent, the retrovirus now known as HIV, was first described in May 1983 (Barré-Sinoussie et al. 1983; Gallo et al. 1983), and its role as the cause of AIDS was established the following year (Gallo et al. 1984; Sarngadharan et al. 1984).

Following this achievement, the focus of epidemiological research shifted to clarifying the routes of transmission. This focus did not put an end to behavioral research, but resulted in a shift in the types of behavioral contrasts investigated. Whereas prior research was focused on presumed behavioral differences between homosexual males and the rest of the population (that is, group-level differences), the availability of an HIVantibody test facilitated cross-sectional and prospective studies of prevalent and incident HIV infection and its association with specific behaviors among homosexual men (that is, individual-level differences) (for examples, see Goedert et al. 1984; Melbye et al. 1984; Nicholson et al. 1985; Boyko et al. 1986; Evans et al. 1986; Mayer et al. 1986; Schechter et al. 1986; Kingsley et al. 1987; Moss et al. 1987; Darrow et al. 1987; Winkelstein et al. 1987). These studies identified receptive anal intercourse and multiple sexual partners as the strongest and most consistent predictors of infection among men who have sex with men (Caceres and van Griensven 1994). Similar behavioral comparisons in studies of injection-drug users pointed to the sharing of needles as the primary mode of transmission in those populations (Chaisson et al. 1987 and 1989; Schoenbaum et al. 1989; Vlahov et al. 1990). Likewise, studies of heterosexuals, especially in sub-Saharan Afri$\mathrm{ca}$, indicated that having multiple heterosexual partners was the key behavioral risk factor there, and suggested that male-to-female transmission was more efficient than female-to-male transmission during penile-vaginal intercourse (Quinn et al. 1986; Padian 1987; Johnson 1988; Johnson and Laga 1988).

Thus, during the first several years after the recognition of AIDS, between-group behavioral comparisons guided the search for the etiologic agent, and withingroup behavioral variations helped to identify the primary routes of transmission. As the 1980s drew to a close, behavior continued to occupy a central position in HIVrelated research, but its role shifted from independent to dependent variable. The rationale for this shift was clear. In the absence of a cure or vaccine, behavior change was the only obvious means available for controlling the spread of HIV. This sentiment was articulated as early as 1984 (see William 1984), and became a widely paraphrased dictum among AIDS researchers and health officials during the next dozen years (Curran 1985; Chin and Mann 1990; World Bank 1997). Accordingly, some investigators set out to identify the individual-level psychosocial correlates of behaviors by which HIV is transmitted (Hayes et al. 1990; Penkower et al. 1991; Basen-Engquist 1992; Peterson et al. 1992; Taylor et al. 1992; Perkins et al. 1993; Simpson et al. 1993; Catania et al. 1994; Stokes and Peterson 1998). Others developed generalized theoretical frameworks for the design of HIV-transmission-prevention programs, such as the AIDS Risk-Reduction Model (Catania et al. 1990 and 1994) and the Information-MotivationBehavioral Skills Model (Fisher and Fisher 1992; Fisher et al. 1994). Still others developed and evaluated behavioral interventions targeting these psychosocial antecedents (Rickert et al. 1990; Kelly et al. 1991; Jemmott et al. 1992; Kipke et al. 1993; St. Lawrence et al. 1995). Several books on behavioral approaches to HIV prevention were published (for example, Valdiserri 1989; DiClemente and Peterson 1994). A few commentators (for example, Fineberg 1988) expressed doubt that large reductions in behavioral risk could be achieved and maintained in all populations, but even the skeptics conceded that a concerted effort must be made.

\section{Growing Interest in Biological Mechanisms}

Although enthusiasm for behavioral explanations and interventions persisted well into the 1990s, that decade was characterized also by a growing interest in biological mechanisms that influence per-contact transmission 
probabilities. The first such mechanism to capture the attention of HIV epidemiologists was the presence of other sexually transmitted infections (STIs). Statistical associations at the individual level between HIV / AIDS and other STIs were documented as early as 1983 (for example, Jaffe et al. 1983b; Piot et al. 1984). During the next several years, investigators identified numerous pathways by which other STIs might increase not only susceptibility to HIV (Weber et al. 1986; Quinn et al. 1987) but also the infectiousness of individuals already carrying the virus. Wasserheit's (1992) seminal study provides an excellent summary of this research and its implications for synergistic interactions between HIV and other STIs at the individual and population levels (for recent reaffirmations, see Fleming and Wasserheit 1999; Corbett et al. 2002).

The first scientific test of the usefulness of biomedical treatment of other STIs as a strategy for reducing the spread of HIV at the population level was undertaken in the Mwanza District of Tanzania in the early 1990s. In this cluster randomized trial (Hayes et al. 1995), intensive syndromic management of bacterial STIs resulted in a 40 percent reduction in HIV incidence in treatment relative to control communities (Grosskurth et al. 1995). The initial optimism among HIV epidemiologists at this result gave way to disappointment and consternation when STI-treatment campaigns apparently failed to reduce HIV incidence in two subsequent community randomized trials conducted in Uganda (Wawer et al. 1999; Kamali et al. 2003). As a result, HIV epidemiologists have now turned their attention from the treatment of bacterial STIs to the management of herpes simplex virus type 2 infection in hopes that suppressing reactivation of this chronic infection may help reduce both susceptibility to and the infectiousness of HIV (Celum et al. 2004; Corey et al. 2004; Wald 2004). Early results are not encouraging (Celum et al. 2008).

A second biological determinant of the per-contact transmission probability of HIV infection is male circumcision. Epidemiological interest in this mechanism dates to the late 1980s, when a prospective study of men in Nairobi, Kenya, showed that HIV incidence was more than eight times higher among uncircumcised men than among their circumcised counterparts (Cameron et al. 1989). Shortly thereafter, two ecological studies (Bongaarts et al. 1989; Moses et al. 1990) showed a strong inverse association between the proportion of males who were circumcised and the level of adult HIV prevalence among geographically defined sub-Saharan African populations. Since that time, numerous cross-sectional, casecontrol, and prospective studies of men in various parts of Africa (Malamba et al. 1994; Seed et al. 1995; Quigley et al. 1997; Urassa et al. 1997; Lavreys et al. 1999) and the
United States (Kreiss and Hopkins 1993) have provided further support for this association (see O'Farrell and Egger 2000 for a review).

Beginning in the mid-1990s, these findings prompted some epidemiologists to suggest the use of circumcision services for newborn and adult males in sub-Saharan Africa as a strategy for slowing the spread of HIV (Caldwell and Caldwell 1996; Moses et al. 1998; Halperin and Bailey 1999; Weiss et al. 2000). This position has been bolstered greatly by the results of three separate randomized controlled trials of male circumcision (Auvert et al. 2005; Bailey et al. 2007; Gray et al. 2007), all revealing substantial protective effects of male circumcision. Accordingly, UNAIDS (2007) now recommends that male circumcision be recognized as an important HIV-transmission-prevention strategy, and resources from international public health organizations are now being mobilized to offer male circumcision services in sub-Saharan Africa and beyond.

Epidemiologists have also studied possible genetic influences on per-contact transmission probabilities of HIV infection (Kaslow et al. 2005), but we do not consider them here. Rather, we discuss treatment with highly active antiretroviral therapy (HAART) because of its potential policy relevance. The primary purpose of HAART is to combat the pathogenic effects of HIV replication among people who are already infected. Yet because HAART dramatically suppresses the concentration of HIV in the serum and genital secretions of treated people (Gulick et al. 1997; Gupta et al. 1997; Hammer et al. 1997; Vernazza et al. 1997), it is also believed to reduce the per-contact probability of transmitting HIV to uninfected partners (Quinn et al. 2000; Gray et al. 2001). These epidemiological consequences remain uncertain because any reduction in the per-contact transmission probability could be offset by increases in the duration of infectiousness and, perhaps, by changes in behavior. These issues have been considered in several simulation studies (Blower et al. 2000; Law et al. 2001; Gray et al. 2003; Abbas et al. 2006; Baggaley et al. 2006), as we discuss in greater detail below. In spite of this uncertainty, the potential epidemiological impacts have been an important impetus to recent efforts to make low-cost antiretroviral therapy available to HIV-infected people throughout the developing world (Muntaner et al. 2006).

\section{Skepticism about Behavioral Mechanisms and Interventions}

No necessary mutual exclusivity exists between explanations focused on biological mechanisms and those focused on behaviors. In fact, policy statements frequently 
emphasize the need to integrate biomedical and behavioral components into comprehensive HIV-control strategies (UNAIDS 2007; Coates et al. 2008; Merson et al. 2008; Padian et al. 2008; Piot et al. 2008). Nevertheless, the growing focus on biological mechanisms during the 1990s was accompanied by a mounting skepticism about the contribution of behavioral variations to inequalities in the spread of HIV, as well as a rising pessimism about the potential effectiveness of behavioral interventions.

This skepticism had several causes. One was the lack of consistent evidence of population-level variations in behavior corresponding in the expected way to variations in the severity of HIV epidemics. By the 1990s, HIV epidemiologists shifted their attention from identifying contrasts between gay men and injection-drug users on the one hand and the so-called general population on the other, to seeking explanations for the severe epidemics of heterosexually transmitted HIV infection underway in parts of sub-Saharan Africa (Clumeck et al. 1984; Piot et al. 1984; Van de Perre et al. 1984). These epidemics were perplexing because no large-scale, self-sustaining epidemics of heterosexually transmitted HIV had emerged in the United States or Europe (Quinn et al. 1986; Padian 1987; Piot et al. 1988), and because studies of HIV-infected hemophiliacs and their wives in the United States suggested that HIV transmission during penile-vaginal intercourse was extremely inefficient (Kreiss et al. 1985). What, then, could explain these African epidemics?

Two primary hypotheses emerged (Biggar 1986) centered on (1) some biological cofactor (for example, other STIs) or (2) some difference in sexual behavior. Evidence for the former hypothesis was available in the form of high STI rates (Osoba 1981) and corresponding infertility (Belsey 1976) in parts of sub-Saharan Africa. Evidence that rates of sex-partner change (or other relevant behavioral parameters) were higher in sub-Saharan Africa than in the United States or Europe, however, was sketchy. No effort to collect comparable data on sexual practices in United States, European, and African populations using representative sampling and standardized interview methods had ever been undertaken. In the absence of such systematic data, some investigators drew upon information from case reports to suggest that heterosexual "promiscuity" played an important role in Africa's HIV epidemics (Clumeck et al. 1985; Hrdy 1987). Others, citing lack of evidence, cautioned against racist stereotypes (Miller and Rockwell 1988).

Caldwell and his colleagues (1989) and Larson (1989) sought to overcome the lack of comparative survey data by compiling information from a large number of ethnographic studies conducted over many decades by anthropologists in different parts of sub-Saharan Africa. Both studies concluded that arrangements involving multiple sexual partners were common throughout the region and drew inferences about rates of partner change and patterns of sexual contact, linking these practices to kinship systems, changing economic circumstances, and cultural values in sub-Saharan Africa. Some of their conclusions were highly controversial (see Le Blank et al. 1991; Ahlberg 1994), and other investigators characterized this work as "heir to a deeply rooted legacy of Western racism" (Schoepf 1993:66), which may have had a chilling effect on this line of inquiry.

The first systematic comparative data on sexual practices in developing countries were published by the World Health Organization in 1995 (Cleland and Ferry 1995). That report provided evidence of high rates of premarital and extramarital sexual contact and multiple partnerships (Caraël 1995; Caraël et al. 1995) and low levels of condom use (Mehryar 1995) in several sub-Saharan African countries. For instance, whereas only 3 percent and 1 percent of unmarried males in Singapore and Sri Lanka, respectively, reported having sexual intercourse in the prior 12 months, the corresponding figures for Kenya, Lesotho, and Tanzania were 54 percent, 37 percent, and 33 percent (Caraël 1995). Moreover, whereas 66 percent and 52 percent of sexually experienced men in Singapore and Thailand reported ever using condoms, the corresponding figures for Kenya, Lesotho and Tanzania were 16 percent, 14 percent, and 16 percent (Mehryar 1995).

Since that time, several investigators have sought to establish the relative contributions of behavioral and biological mechanisms to variations among parts of subSaharan Africa in the severity of local HIV epidemics. The most ambitious of these projects was undertaken by the Study Group on Heterogeneity of HIV Epidemics in African Cities (Buvé et al. 2001). This team collected extensive biological and behavioral data from representative samples of adults in four sub-Saharan African cities with widely varying levels of HIV prevalence. They found that behavioral variables strongly associated with the risk of $\mathrm{HIV}$ at the individual level within each city did not vary widely between cities. In contrast, they found substantial cross-city differences in rates of male circumcision and of ulcerative STIs. The team concluded, therefore, that "differences in risky sexual behavior are outweighed by differences in factors influencing HIV transmission probability" (page 30). A similar study focusing on rural areas reached the same conclusion (Boerma et al. 2003).

In the United States, HIV epidemiologists were increasingly focused on the growing concentration of the HIV epidemic among racial and ethnic minority groups, especially African Americans (Karon et al. 2001). As in sub-Saharan Africa, efforts to explain this pattern tended 
to pit the contributions of behavioral mechanisms against those of biological determinants (for reviews, see Smith et al. 2000; Millett et al. 2006). Overall, male circumcision in the United States appears to be more common among whites (81 percent) than among African Americans (65 percent), but this gap is narrower (and statistically insignificant) in younger cohorts (Laumann et al. 1997). Ulcerative STIs are markedly more common among African Americans than whites according to both passive surveillance data (Nakashima et al. 1996) and seroprevalence surveys (Fleming et al. 1997), suggesting that these STIs may well play a role. The contribution of behavioral mechanisms remains unclear, due in part to the countervailing influences of different behaviors. Data from nationally representative surveys show that African American adolescents and adults are more likely than whites to report having large numbers of sexual partners (Billy et al. 1993; Leigh et al. 1993; Ericksen and Trocki 1994; Laumann et al. 1994; Ku et al. 1998 and 2002; Holtzman et al. 2001). Yet most surveys also show that African Americans are more likely than whites to report using condoms (Sonenstein et al. 1989 and 1998; Tanfer et al. 1993; Holtzman et al. 2001; Anderson 2003).

\section{A New Focus on Structural Constraints}

During the 1990s, as the inequalities of greatest interest to HIV epidemiologists changed, the contribution of behavioral mechanisms became less clear. Interest in behavioral mechanisms was also quelled by the growing recognition that behavioral risk for HIV is often deeply intertwined with people's social and economic circumstances, which in turn depend upon powerful macrosocial forces far beyond the reach of standard health-promotion programs. Scholarly publications on this theme began to emerge in the late 1980s, just as epidemiologists were beginning to grapple seriously with the severity of the HIV epidemics in sub-Saharan Africa. Schoepf, for example, wrote in 1988 that "AIDS has emerged and spread in Central Africa as a result of a set of historically specific economic and social relations" (page 626). One result of these circumstances was a "proliferation of multiple partner strategies" (page 628), which for women was largely motivated by a lack of alternative means of obtaining the basic necessities of life. The three factors identified by Schoepf-poverty, male labor migration, and the subordinate status of womenwould be implicated again and again in the burgeoning literature on the social contexts of sexual behaviors and HIV infection in sub-Saharan Africa (for example, Ankrah 1991; Bassett and Mhloyi 1991; Caravano 1991; Jochelson et al. 1991; Sanders and Sambo 1991; de Bruyn 1992; Ulin 1992; Decosas et al. 1995; Lurie et al. 1995).
One byproduct of this structural view was a gnawing pessimism among HIV epidemiologists concerning whether people could or would change their sexual behaviors to an extent that would be sufficient to contain the spread of HIV. As early as 1993, for example, in a major review article on the epidemiology of HIV in subSaharan Africa, Hunter enumerated the socioeconomic barriers to behavior change and concluded that "these issues of socioeconomic development vastly complicate the search for effective strategies to influence sexual behavior in Africa" (page 69). Another review, published two years later, argued that the standard approaches to behavior change, rooted in clinical and social psychology, "have limited utility when considering social and environmental determinants of HIV infection" (Tawil et al. 1995: 1,299). The authors called for the development and evaluation of interventions that would change socioeconomic circumstances and thereby remove barriers to precautionary behavior, but offered few concrete suggestions regarding the form such interventions might take. Five years later, when the journal AIDS published a special issue devoted to structural factors in HIV prevention (Sumartojo 2000), there were still precious few examples of true structural interventions that the journal could suggest. The situation remains largely unchanged today (Gupta et al. 2008).

Meanwhile, the aggressive advance of HIV epidemics into Southern Africa, in spite of widespread knowledge of the modes of transmission and means of prevention, seemed to confirm the view that behavioral risk was too deeply embedded within powerful social forces to be changed substantially. The history of South Africa's epidemic is perhaps the quintessential, if also the most extreme, example. As late as 1988, data from blood banks suggested that HIV prevalence in adult males and females, both African and white, remained well below one tenth of one percent in South Africa (Schoub et al. 1988). In 1990, although AIDS case reports were increasing, it still seemed possible to avert a severe HIV epidemic in that country if the appropriate steps were taken in time (Zwi and Bachmayer 1990). Some steps were taken, yet HIV prevalence increased inexorably throughout the 1990s, surpassing 20 percent nationally and 30 percent in the province of Kwa Zulu/Natal by the end of the decade (Williams and Gouws 2001). Today the South African epidemic stands as one of the most severe in the world, with adult prevalence estimated at 18 percent (UNAIDS 2008). That this epidemic, which in theory could have been averted, was allowed to unfold into such a devastating tragedy is, to many observers, a testimony to the intransigence of sexual behaviors tied to entrenched social determinants (Campbell 2003; Allen 2004). 
In this context, the appeal of relatively simple interventions targeting biological determinants of per-contact transmission probabilities became undeniable. If providing antibiotics to people with STI symptoms or providing circumcision services to uncircumcised men could substantially reduce susceptibility or infectiousness, potentially thousands of infections could be prevented and thousands of lives saved at minimal cost without requiring the amelioration of poverty, a restructuring of regional labor markets, or the elevation of women's status.

\section{Reconsidering the Importance of Behavior}

Although gravitation toward biological mechanisms and away from behavioral determinants to reduce the spread of HIV is understandable given these circumstances, compelling arguments favor sustaining emphasis on behaviors in HIV epidemiology. We highlight several of these arguments below.

The first involves the nonlinear relationship between behavioral risk and HIV prevalence at the population level, which suggests that large reductions in HIV prevalence may be realized by small changes in behavior. Figure 1 presents a graph of the equilibrium prevalence of HIV infection as a function of the rate of partner change in a hypothetical population. The curve in this graph is derived from the equation $P^{*}=1-1 / R_{0}$ with the background mortality rate set to $\mu=0.02$, the HIV-specific mortality rate set to $k=0.10$, and the per-partnership transmission probability set to $\beta=0.06$. In such a population, a rate of partner change of two partners per year is the threshold for epidemic take-off. At a partner-change rate of 2.1 per year, the equilibrium prevalence of HIV would be 5 per-

Figure 1 Nonlinear relationship between behavior and HIV prevalence in a simple model

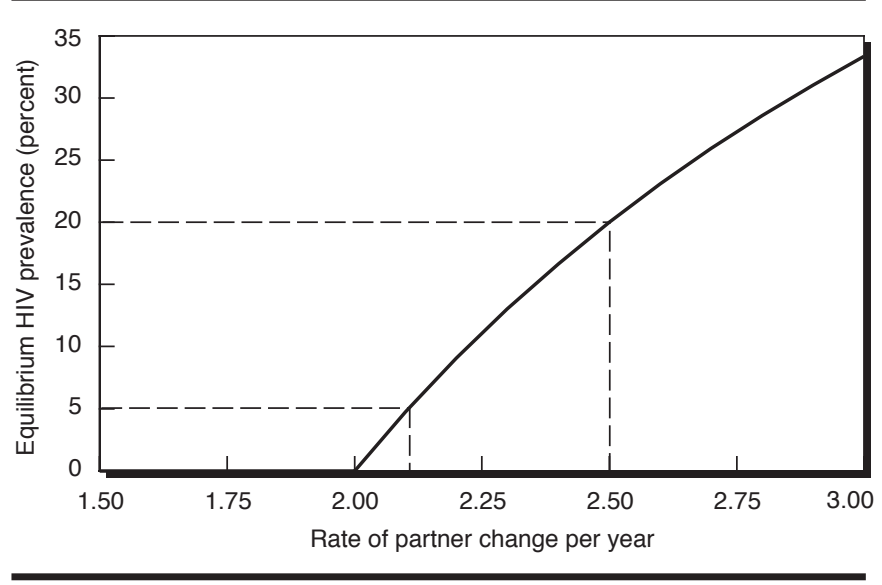

cent, but a partner-change rate of 2.5 per year would lead to an equilibrium prevalence of 20 percent. Thus, a small difference in the rate of partner change leads to a fourfold difference in the equilibrium prevalence of HIV, a difference similar in magnitude to that between the countries of Southern Africa and those of West Africa. The underlying model is simple, but the basic conclusion is widely applicable: small variations in behavior-variations that would be extremely difficult to detect in behavioral surveyscan translate into substantial variations in the spread of HIV. The findings of the Four African Cities study (Buvé et al. 2001) must be interpreted with this possibility in mind. A further implication of this nonlinearity is that small reductions in behavioral risk may have dramatic population-level impacts on HIV prevalence. ${ }^{4}$

A second motivation for ongoing research on behavioral mechanisms in HIV epidemiology is the growing evidence that, across a wide range of settings, people can and do alter their sexual and drug-use practices in response to the spread of HIV. In the early 1980s, substantial declines in the incidence of gonorrhea provided the first indication of sharp behavioral changes among men who have sex with men in the United States (Judson 1983; CDC 1984) and elsewhere (Weller et al. 1984). Further evidence came from surveys of community samples of gay and bisexual men (McKusick et al. 1985a and 1985b; Martin 1987; Ekstrand and Coates 1990). Similar behavioral changes appear to have occurred among heterosexual teenagers and young adults in the United States (Sonenstein et al. 1998). The adoption of risk-reducing practices has also been documented among injection-drug users in the United States (Des Jarlais et al. 1986 and 2000) and elsewhere (Des Jarlais et al. 1994; Peters et al. 1994), including several Asian and sub-Saharan African countries (Nelson et al. 1996; Killian et al. 1999; Stoneburner and Low-Beer 2004; Gregson et al. 2006). These changes were not always rapid or dramatic, but they raise important questions about the individual and collective processes by which behavior change occurs and, in particular, about how HIV-transmission-prevention programs can help facilitate those processes. Recognizing this potential is especially important in light of the implication of the figure-that small behavioral shifts may reap large rewards in halting the spread of HIV.

Another impetus for further research on behavioral mechanisms in HIV epidemiology is that our current picture of population similarities and differences with regard to sexual behaviors may be considerably distorted by differential reporting bias in the extant research. Surveys covering sexual practices have become commonplace in developed and developing countries alike, spurred to a large extent by the spread of HIV (Curtis and Sutherland 2004). Yet the question remains: What can accurately be 
inferred from these self-reported data? Investigators have long been aware of the possibility of receiving inaccurate information in survey interviews, especially where sensitive behaviors are the topic (for example, see Bleek 1987). Indeed, in their 1989 paper, Caldwell and his colleagues cautioned that "international survey programs concerning sexual practices are likely to be hardly worth the paper on which they are printed" (page 226). HIV epidemiologists are acutely aware of the shortcomings of self-reported sexual behavior data (Aral and Peterman 1996; Fishbein and Pequegnat 2000; Cleland et al. 2004). Researchers comparing such data collected from the same people using multiple methods have found alarming levels of inconsistency and troubling signs of underreporting (Plummer et al. 2004; Gallo et al. 2006). Some researchers even refuse to study self-reported sexual behaviors, preferring instead to use perceived risk of HIV infection as a proxy variable (Smith and Watkins 2005). These observations point to the need for ongoing methodological work to improve our ability to obtain accurate information about sensitive behaviors in diverse populations (Mensch et al. 2003; Gregson et al. 2004).

Another important reason for continued behavioral research in HIV epidemiology involves the recognition that the spread of HIV depends upon properties of sexual networks that are not fully captured by standard measures of individual risk, such as numbers of partners and frequency of condom use. Perhaps the most important is concurrency. Classical models of STI transmission implicitly assume that partnerships occur sequentially and do not overlap in time. When multiple partnerships are maintained concurrently, however, a newly infected person can quickly pass the infection along to several other partners. Therefore, even holding the overall number of partners per person-period constant, sexual networks characterized by high levels of concurrency have greater potential for propagating HIV. This idea was proposed in the 1990s on the basis of mathematical models and simulation studies (Watts and May 1992; Morris and Kretzschmar 1995 and 1997; Kretzschmar and Morris 1996). Since then, epidemiologists in the United States have found, in both national and city-specific samples, that African Americans' sexual networks are characterized by higher levels of concurrency than those of whites (Adimora et al. 2002; Manhart et al. 2002). Concurrency, then, may help to explain racial disparities in HIV prevalence in the United States. It may also help explain the aggressive spread of heterosexually transmitted HIV in sub-Saharan Africa (Halperin and Epstein 2004; Epstein 2007), although few systematic studies of levels of concurrency in sub-Saharan African sexual networks have been published to date (but see Lagarde et al. 2001). Further research is needed, therefore, not only to establish levels of concurrency in the sexual networks of various populations, but also to link concurrency and perhaps other network properties to other features of social organization.

A fifth reason for continued research on behavioral mechanisms is the likelihood that social structural or cultural forces may impede attempts to realize the theoretical promise of interventions targeting aspects of HIV risk, be they behavioral or biological. Although the difficulties of mounting successful behavior-change interventions are acknowledged, similar challenges face attempts to target biological risk. The success of biomedical interventions necessary to alter susceptibility or infectiousness is likely to be partial if efforts fail to recognize or account for contextual mediators. For example, a man's willingness and ability to be circumcised or to access and adhere to medical therapies are likely to be culturally mediated by population-specific opportunities and constraints. A related point is that most so-called biological mechanisms have behavioral components. Male circumcision is not only a status but also an act; other sexually transmitted infections also involve behavioral components at the exposure and treatment stages.

Once their effectiveness is established, interventions targeting susceptibility or infectiousness will have a reduced epidemiological impact if they are undermined by behavioral risk compensation, suggesting another compelling reason for continued research on behavioral mechanisms. For example, when interventions such as male circumcision or STI treatment succeed in reducing susceptibility or infectiousness, some people may respond to these changes by increasing their rate of partner change, decreasing their use of condoms, or otherwise changing their behavior in ways that could partially or even fully counteract the positive epidemiological effects of these interventions. The idea of risk compensation has a long history in the injury-prevention and public health literature (for a review, see Hedlund 2000). Although this possibility remains controversial in the HIV epidemiology literature, one group recently opined that risk compensation may be the "Achilles' heel" of interventions targeting the biological determinants of HIV transmission (Cassell et al. 2006).

The nature and magnitude of behavioral risk compensation that may occur in different populations in response to interventions targeting biological mechanisms remain empirical questions. Ignoring the possibility of risk compensation, however, may lead epidemiologists to overstate the potential impacts of those interventions. Examples of this overstatement may be found in the use of simulation models to predict the impact of alternative STI-control programs on future HIV incidence and prevalence. One research group that used this approach predicted that a 50 percent reduction in the duration of 
all STI episodes would prevent 43 percent of new HIV infections over a ten-year period in a Ugandan population (Robinson et al. 1995; see also Korenromp et al. 2000; Nagelkerke et al. 2002). More recently, epidemiologists used a simulation model to predict that universal circumcision of sub-Saharan African males would avert 5.7 million HIV infections and three million deaths over a 20-year period (Williams et al. 2006).

In these studies, investigators assumed that dramatic changes in rates of STIs or male circumcision would have no impact on sexual behavior. Had they assumed instead that people would increase their rates of partner change or decrease their use of condoms in response to decreased susceptibility or infectiousness, they might have concluded that STI-control programs or male circumcision would have more modest or even adverse impacts on future HIV incidence and prevalence.

The latter outcome, indeed, corresponds exactly to what investigators found in their efforts to predict the impacts of HAART on HIV incidence and prevalence using simulation studies. One group, for example, sought to predict the impact of HAART on HIV incidence and mortality among gay men in San Francisco. After conducting simulations under a range of alternative behavior-change scenarios (Blower et al. 2000), the researchers concluded that widespread use of HAART could reduce future HIV incidence and mortality, but only if risky behavior did not increase substantially. They wrote, "An increase in risky behavior of only 10 percent was enough to counterbalance the benefits of ART. Greater increases in risk behavior resulted in the incidence rate increasing and hence effectiveness becoming negative" (page 653). Similar conclusions have emerged from simulation studies of the effects of HAART on HIV prevalence in other populations, including gay men in Australia (Law et al. 2001) and heterosexuals in Uganda (Gray et al. 2003), Malawi (Baggaley et al. 2006), and other parts of sub-Saharan Africa (Abbas et al. 2006). These findings point to the need for research to quantify the behavioral effects of interventions targeting biological mechanisms, especially when those interventions are implemented on a large scale rather than in carefully monitored clinical trials.

\section{Modifying HIV Epidemiology's Conceptual Model}

Several observations in the preceding section raise serious concerns about the usefulness of the formula $R_{0}=c \beta D$ as a guiding principle for research on the epidemiology of HIV infection. According to that model, all inequalities in the spread of HIV must be attributable to some combination of (1) variations in patterns of sexual and needle- sharing contact, summarized in the parameter $c$; (2) variations in the biological determinants of susceptibility and infectiousness, summarized in $\beta$; and (3) variations in the duration of infectiousness, summarized in $D$. Variations in these proximate determinants may be attributable, in turn, to more remote social, economic, or political factors. The model assumes, however, that these factors operate through the proximate determinants (Boerma and Weir 2005). We do not dispute the role of proximate mechanisms in mediating the influences of social factors, but we argue that two key simplifying assumptions implicit in the equation $R_{0}=c \beta D$ are unrealistic and that this conceptual model, therefore, requires modification. These simplifying assumptions are, first, that the patterns of sexual contact and needle-sharing practices in a population are exogenously fixed rather than dependent upon prevailing epidemiological circumstances, and second, that these practices do not depend systematically upon other model parameters.

We have already cited research suggesting that people change their behaviors in response to the threat of HIV. This finding appears to apply broadly to populations as diverse as men who have sex with men in the United States, injection-drug users in the United Kingdom, and heterosexual women and men in Uganda and elsewhere in sub-Saharan Africa. These findings are clearly at odds with the equation $R_{0}=c \beta D$, in which behaviors are summarized in a fixed parameter, $c$, and they suggest that our conceptual model should be altered to accommodate the possibility of behavior change. One simple way of accomplishing this would be to replace the parameter $c$ with a behavior-change function $c(P)$ that describes how people reduce their number of partners, increase their use of condoms, or take other precautionary measures in response to increases in HIV prevalence. Indeed, some economists have adopted this strategy (Kremer 1996; Kremer and Morcom 1998). In most cases, the assumption may be reasonable that the behavior-change function for a given population takes an initial value $c_{0}$ when HIV prevalence is zero and that it decreases smoothly with increasing prevalence thereafter.

In this revised formulation, the standard equation for equilibrium prevalence would no longer be accurate. Instead, it would be replaced by

$$
P^{+}=1-D /\left[c\left(P^{+}\right) \beta\right],
$$

where $c\left(P^{+}\right)$is the level of behavioral risk that prevails when prevalence has reached its equilibrium level. This equation defines the equilibrium prevalence only implicitly. Depending upon the specification of $c(P)$, solving the equation to find an explicit expression for $P^{+}$in terms of $\beta, D$, and the parameters of the behavior-change function may or may not be possible. In general, however, as 
long as $c(P)$ is a decreasing function, the new equilibrium prevalence is less than that given by $P^{*}=1-1 / R_{0}$.

Clearly, this formulation, too, is a simplification. It assumes that the population responds instantaneously to changes in HIV prevalence. Yet several investigators (for example, Macintyre et al. 2001) suggest that behavior change occurs not in response to changes in HIV prevalence per se, but rather to changes in HIV-related mortality. This possibility, combined with the long incubation period of HIV, suggests that behavior change may lag several years behind changes in HIV prevalence. Moreover, other investigators have emphasized that behavior change in response to the spread of HIV is only partially a matter of individual choice and should also be regarded as a collective process by which people evaluate the threat of infection and consider alternative behavioral responses (Watkins 2004; Smith and Watkins 2005). These collective processes take time, generating a further lag between increasing prevalence and consequent behavioral change. Nevertheless, replacing the behavior parameter $c$ with a behavior-change function $c(P)$ in our conceptual model would go a long way toward introducing a useful element of dynamism into epidemiological thinking about the spread of HIV.

The standard formulation of $R_{0}=c \beta D$ rests upon an additional simplifying assumption that we dispute: that behavior is independent of other model parameters. One way in which this assumption could be violated is if behavioral risk-or behavior change-depended systematically on susceptibility. Yet this dependency is exactly what numerous models of health behavior predict. The Health Belief Model (Strecher and Rosenstock 1997) holds that perceived susceptibility is a key determinant in the adoption of risk-reducing behavior for a broad range of health outcomes, and similar thinking is central to the AIDS Risk Reduction Model (Catania et al. 1990). The dependence of behavior upon perceived susceptibility is also apparent in our prior discussion of behavioral risk compensation. When exogenous factors create decreases in individual susceptibility to HIV infection, some affected people may respond by increasing their level of behavioral risk, since their incentive to take precautionary measures has been reduced.

This response is not the only way in which behavior could depend systematically upon other model components. Another possibility is that behavior-or behavior change-could be conditioned by the mortality parameters $\mu$ and $k$. As noted above, in simple models $\mu$ is the background mortality rate in the population and $k$ is the HIV-specific mortality rate among infected people, leading to $D=1 /(\mu+k)$. Behavior may depend upon $k$ for the obvious reason that people are more likely to take precautions against diseases that can kill them quickly. This idea is widespread in the health-behavior literature. In the Health Belief Model, for example, it takes the form of the perceived severity construct (Strecher and Rosenstock 1997). In the case of HIV epidemics, individuals might partially abandon precautionary measures if the disease became less often fatal (as a result, for example, of the widespread availability of HAART), or they might increase their use of precautionary behaviors if the disease became more often fatal (as a result, for example, of genetic mutation in the virus). Behavior and behavior change might also depend upon the background mortality rate, $\mu$. This notion has been expressed by several investigators. Writing about the problems of violence and HIV infection among urban minority populations in the United States, for example, Dow and his colleagues (1999) point out, "People who will die young from violence have little incentive to protect against HIV" (page 1,369). Other investigators (Zwi and Cabral 1991; Caldwell 2000) have articulated similar views about the role of mortality from competing risks in shaping behavioral responses to the spread of HIV in sub-Saharan African populations.

Putting these ideas together suggests that the behavior parameter $c$ in the standard formulation of the conceptual model should be replaced not just by a behavior-change function, $c(P)$, but also by a mortalityand susceptibility-dependent behavior-change function, $c(P ; \beta, \mu, k)$. In such a formulation, the mortality and susceptibility parameters would operate in two distinct ways to influence the spread of HIV. First, they would operate directly, as they do in the standard formulation, to influence the per-contact transmission probability and the duration of infectiousness. Second, they would operate indirectly through their influences on behavior and behavior change. In many circumstances, the direct and indirect effects are likely to operate in countervailing directions; in other cases, they could be mutually reinforcing.

A conceptual model based upon a mortality- and susceptibility-dependent behavior-change function may have limited empirical usefulness. Like the standard formulation, it treats background and HIV-specific mortality rates, as well as susceptibility and infectiousness, as exogenously determined population parameters. It also collapses diverse sources of influence on susceptibility and infectiousness into a single, exogenously-fixed population parameter. Although, unlike the standard formulation, it allows behavior to change in response to changes in prevalence, and it allows those changes to depend upon other model parameters, it provides little guidance on the specification of $c(P ; \beta, \mu, k)$ beyond the aforementioned unrealistic assumption that behavior change occurs instantaneously in response to changes in prevalence.

The potential value of this revised formulation, therefore, lies not so much in how we model the spread of 
HIV in populations, but rather in how we think about the processes by which HIV spreads and in what types of research questions we pose about those processes. The standard formulation promotes static thinking about the determinants of the spread of HIV in populations and contributes to a division in HIV epidemiology between those who think that behavioral factors are more important and those who think that biological determinants of susceptibility and infectiousness play more important roles. Epidemiological researchers and international policy-setting institutions alike increasingly recognize that the division between research and prevention efforts has become an impediment to effective action to limit the spread of HIV (UNAIDS 2007). In their contribution to a recent series of essays in The Lancet about the future of HIV prevention, for example, Merson and his colleagues called for "combination prevention-i.e., a combination of behavioural, structural, and biomedical prevention paradigms and approaches adapted and prioritized to specific contexts" (2008: 485). This call was echoed in other contributions to the series (Coates et al. 2008; Padian et al. 2008; Piot et al. 2008).

To be sure, part of the challenge to achieving the vision of combination prevention is institutional. Often, one set of organizations is specialized for behavioral interventions, whereas another set is specialized for biological or biomedical ones, and the two sides compete for scarce resources rather than collaborate in the formulation of a coherent, multipronged strategy. Solving this institutional problem is important, but may not be sufficient. Altering our core conceptual model in ways that make explicit the interdependency of behavioral and biological mechanisms may be equally necessary. The alternative formulation that we propose, although unrealistic in some ways, may help to promote more dynamic thinking among HIV epidemiologists and at the same time may create opportunities for a constructive reconciliation of the behavior and biology camps.

\section{Notes}

1 We acknowledge that our focus is mainly on sexual behaviors rather than on the sharing of injection-drug equipment or other behaviors by which HIV is transmitted. This focus reflects our greater familiarity with the research literature on sexual transmission.

2 The distinction between behavioral and biological mechanisms, employed widely in the epidemiological literature, is somewhat artificial, for behaviors are governed, at least in part, by neuroendocrine systems and thus are not wholly outside the realm of biology. Likewise, most of the factors that are conventionally placed in the biological category have substantial behavioral components. Thus, although the distinction between behavioral and biological mechanisms may be analytically convenient, it is also arbitrary.
3 Models of this type, typically specified as systems of differential equations, have a long history in infectious disease epidemiology (Kermack and McKendrick 1927; Hethcote 1976). They were first applied to sexually transmitted HIV in the mid-1980s (Anderson et al. 1986; May and Anderson 1987). In these models, the theoretical significance of $R_{0}$ - the basic reproductive number-is then threefold (Anderson et al. 1986; May and Anderson 1987; Anderson 1999). First, its value determines whether ongoing transmission of HIV can be sustained in a population. When $R_{0}<1$, each infected person infects fewer than one susceptible person, on average, and therefore an epidemic cannot be maintained. Second, $R_{0}$ is related to the initial growth rate of the epidemic according to the doubling-time equation $t_{d}=0.693 \times D /\left(R_{0}-1\right)$. Third, $R_{0}$ is related to the equilibrium prevalence toward which the epidemic converges over time, which for simple models (and for $R_{0} \geq 1$ ) is expressed as $P^{*}=1-1 / R_{0}$. Thus, $R_{0}$ provides an appealing summary measure of the severity of an HIV epidemic in a population. Technically, these formulas are derived from very simple-and therefore unrealistic-models. More complicated generalizations of the same types of models have proved useful in elucidating several aspects of HIV epidemiology. These include the role of heterogeneity in sexual activity and patterns of mixing between high and low sexual activity classes (Blythe and Anderson 1988; Jacquez et al. 1988; Koopman et al. 1988; Gupta et al. 1989; Garnett and Anderson 1993 and 1994) as well as the epidemiological consequences of the staged progression of AIDS and especially of elevated infectiousness during primary infection (Hethcote and Van Ark 1992; Jacquez et al. 1994; Koopman et al. 1997). These models lead to complex mathematical expressions for $R_{0}$.

4 This assertion contradicts the claim that "radical" behavioral change is required to bring about reductions in HIV transmission at the population level (Coates et al. 2008).

\section{References}

Abbas, Ume L., Roy M. Anderson, and John W. Mellors. 2006. “Potential impact of antiretroviral therapy on HIV-1 transmission and AIDS mortality in resource-limited settings." Journal of Acquired Immune Deficiency Syndromes 41(5): 632-641.

Adimora, Adora A., Victor J. Schoenbach, Dana M. Bonas, Francis E.A. Martinson, Kathryn H. Donaldson, and Tonya R. Stancil. 2002. "Concurrent sexual partnerships among women in the United States." Epidemiology 13(3): 320-327.

Ahlberg, Beth M. 1994. "Is there a distinct African sexuality? A critical response to Caldwell." Africa 64(2): 220-242.

Allen, Tim. 2004. "Introduction: Why don't AIDS policies work?" Journal of International Development 16(8): 1,123-1,127.

Anderson, John E. 2003. "Condom use and HIV risk among US adults." American Journal of Public Health 93(6): 912-914.

Anderson, Roy M. 1999. “Transmission dynamics of sexually transmitted infections." In Sexually Transmitted Diseases (Third Edition). Eds. King. K. Holmes, P. Frederick Sparling, Per-Anders Mardh, S.M. Lemon, Walter E. Stamm, Peter Piot, and Judith N. Wasserheit. New York: McGraw-Hill. Pp. 25-37.

Anderson, R.M., G.F. Medley, R.M. May, and A.M. Johnson. 1986. “A preliminary study of the transmission dynamics of the human immunodeficiency virus (HIV), the causative agent of AIDS." IMA Journal of Mathematics Applied in Medicine and Biology 3(4): 229-263.

Ankrah, E. Maxine. 1991. "AIDS and the social side of health." Social Science EMedicine 32(9): 967-980. 
Aral, Sevgi O. and King K. Holmes. 1999. "Social and behavioral determinants of the epidemiology of STDs: Industrialized and developing countries." In Sexually Transmitted Diseases (Third Edition). Eds. King. K. Holmes, P. Frederick Sparling, Per-Anders Mardh, S.M. Lemon, Walter E. Stamm, Peter Piot, and Judith N. Wasserheit. New York: McGraw-Hill. Pp. 39-76.

Aral, Sevgi O. and Thomas A. Peterman. 1996. "Measuring outcomes of behavioural interventions for STD/HIV prevention." International Journal of STD and AIDS 7(supplement 2): 30-38.

Auvert, Bertran, Dirk Taljaard, Emmanuel Lagarde, Joelle SobngwiTambekou, Remi Sitta, and Adrian Puren. 2005. “Randomized, controlled intervention trial of male circumcision for reduction of HIV infection risk: The ANRS 1265 Trial." PLoS Medicine 2(11): e298.

Baggaley, Rebecca F., Geoff P. Garnett, and Neil M. Ferguson. 2006. "Modeling the impact of antiretroviral use in resource-poor settings." PLoS Medicine 3(4): e124.

Bailey, Robert C., Stephen Moses, Corette B. Parker, et al. 2007. “Male circumcision for HIV prevention in young men in Kisumu, Kenya: A randomised, controlled trial." Lancet 369(9,562): 643-656.

Barré-Sinoussi, F., J.C. Chermann, F. Rey, et al. 1983. "Isolation of a Tlymphotropic retrovirus from a patient at risk for acquired immune deficiency syndrome (AIDS)." Science 220(4,599): 868-871.

Basen-Engquist, K. 1992. “Psychosocial predictors of safer sex behaviors in young adults." AIDS Education and Prevention 4(2): 120-134.

Bassett, Mary T. and Marvellous Mhloyi. 1991. "Women and AIDS in Zimbabwe: The making of an epidemic." International Journal of Health Services 21(1): 143-156.

Belsey, Mark A. 1976. “Epidemiology of infertility: A review with particular reference to sub-Saharan Africa." Bulletin of the World Health Organization 54(3): 319-341.

Biggar, Robert J. 1986. “The AIDS problem in Africa." Lancet 327(8,472): 79-83.

Billy, John O.G., Koray Tanfer, William R. Grady, and Daniel H. Klepinger. 1993. "The sexual behavior of men in the United States." Family Planning Perspectives 25(2): 52-60.

Bleek, Wolf. 1987. "Lying informants: A fieldwork experience from Ghana." Population and Development Review 13(2): 314-322.

Blower, S.M., H.B. Gershengorn, and R.M. Grant. 2000. "A tale of two futures: HIV and antiretroviral therapy in San Francisco." Science 287(5,453): 650-654.

Blythe, S.P. and R.M. Anderson. 1988. "Heterogeneous sexual activity models of HIV transmission in male homosexual populations." Mathematical Medicine and Biology 4(4): 237-260.

Boerma, J. Ties and Sharon S. Weir. 2005. "Integrating demographic and epidemiological approaches to research on HIV/AIDS: The proximate-determinants framework." Journal of Infectious Diseases 191(supplement 1): s61-s67.

Boerma, J. Ties, Simon D. Gregson, Constance Nyamukapa, and Mark Urassa. 2003. "Understanding the uneven spread of HIV within Africa: Comparative study of biologic, behavioral, and contextual factors in rural populations in Tanzania and Zimbabwe." Sexually Transmitted Diseases 30(10): 779-787.

Bongaarts, John, Priscilla Reining, Peter Way, and Francis Conant. 1989. "The relationship between male circumcision and HIV in African populations." AIDS 3(6): 373-377.

Boyko, William J., Martin T. Schechter, Kevin J. P. Craib, et al. 1986. “The Vancouver Lymphadenopathy-AIDS Study: 5. Antecedent behavioural, clinical and laboratory findings in patients with AIDS and
HIV-seropositive controls." Canadian Medical Association Journal 135(8): 881-887.

Brunham, Robert C. 2005. "Insights into the epidemiology of sexually transmitted diseases from $R_{0}=\beta c D$." Sexually Transmitted Diseases 32(12): 722-724.

Buvé, A., M. Caraël, R.J. Hayes, et al. 2001. “The multicentre study on factors determining the differential spread of HIV in four African cities: Summary and conclusions." AIDS 15(supplement 4): s127-s131.

Caceres, Carlos F. and Godfried J.P. van Griensven. 1994. “Male homosexual transmission of HIV-1." AIDS 8(8): 1,051-1,061.

Caldwell, John C. 2000. "Rethinking the African AIDS epidemic." Population and Development Review 26(1) 117-135.

Caldwell, John C. and Pat Caldwell. 1996. "The African AIDS epidemic." Scientific American 274(March): 62-68.

Caldwell, John C., Pat Caldwell, and Pat Quiggin. 1989. "The social context of AIDS in sub-Saharan Africa." Population and Development Review 15(2): 185-234.

Cameron, D. William, J. Neil Simonsen, Lourdes J. D’Costa, et al. 1989 "Female to male transmission of human immunodeficiency virus type 1: Risk factors for seroconversion in men." Lancet (334)8,860: 403-407.

Campbell, Catherine. 2003. Letting Them Die: Why HIV/AIDS Prevention Programs Fail. Bloomington: Indiana University Press.

Caraël, Michel. 1995. "Sexual behaviour." In Sexual Behaviour and AIDS in the Developing World. Eds. John Cleland and Benoît Ferry. London: Taylor and Francis. Pp. 75-123.

Caraël, Michel and King K. Holmes. 2001. "Dynamics of HIV epidemics in sub-Saharan Africa: Introduction." AIDS 15(supplement 4): s1-s4.

Caraël, Michel, John Cleland, Jean-Calude Deheneffe, Benoît Ferry, and Roger Ingham. 1995. "Sexual behaviour in developing countries: Implications for HIV control." AIDS 9(10): 1,171-1,175.

Caravano, Kathryn. 1991. "More than mothers and whores: Redefining the AIDS prevention needs of women." International Journal of Health Services 21(1): 131-142.

Cassell, Michael M., Daniel T. Halperin, James D. Shelton, and David Stanton. 2006. "Risk compensation: The Achilles' heel of innovations in HIV prevention?" British Medical Journal 332(7,541): 605-607.

Catania, Joseph A., Thomas J. Coates, and Susan Kegeles. 1994. “A test of the AIDS Risk Reduction Model: Psychosocial correlates of condom use in the AMEN cohort study." Health Psychology 13(6): 548-555.

Catania, Joseph. A., Susan M. Kegeles, and Thomas J. Coates. 1990. “Towards an understanding of risk behavior: An AIDS risk reduction model (ARRM)." Health Education Quarterly 17(1): 53-72.

Catania, Joseph A., Dennis Osmond, Ronald D. Stall, et al. 2001. “The continuing HIV epidemic among men who have sex with men." American Journal of Public Health 91(6): 907-914.

Celum, Connie, Ruth Levine, Marcia Weaver, and Anna Wald. 2004. "Genital herpes and human immunodeficiency virus: Double trouble." Bulletin of the World Health Organization 82(6): 447-453.

Celum, Connie, Anna Wald, James Hughes, et al. 2008. “Effect of acyclovir on HIV-1 acquisition in herpes simplex virus 2 seropositive women and men who have sex with men: A randomized, doubleblind, placebo-controlled trial." Lancet 371(9,630): 2,109-2,119.

Centers for Disease Control (CDC). 1981a. "Pneumocystic pneumoniaLos Angeles." Morbidity and Mortality Weekly Report 30(21): 250-252. 
1981b. "Kaposi's sarcoma and Pneumocystis pneumonia among homosexual men-New York City and California." Morbidity and Mortality Weekly Report 30(25) 305-308.

. 1981c. "Follow-up on Kaposi's sarcoma and Pneumocystis pneumonia." Morbidity and Mortality Weekly Report 30(28 August): 409-410.

—. 1984. "Declining rates of rectal and pharyngeal gonorrhea among males-New York City." Morbidity and Mortality Weekly Report 33(21): 295-297.

Centers for Disease Control and Prevention (CDC). 2006. HIV/AIDS Surveillance Report, 2006, volume 18. Atlanta: United States Department of Health and Human Services, Centers for Disease Control and Prevention.

Chaisson, Richard E., Peter Bacchetti, Dennis Osmond, Barbara Brodie, Merle A. Sandle, and Andrew R. Moss. 1989. "Cocaine use and HIV infection in intravenous drug users in San Francisco." Journal of the American Medical Association 261(4): 561-565.

Chaisson, Richard E., Andrew R. Moss, Robin Onishi, Dennis Osmond, and James R. Carlson. 1987. "Human immunodeficiency virus infection in heterosexual intravenous drug users in San Francisco." American Journal of Public Health 77(2): 169-172.

Chin, James and Jonathan M. Mann. 1990. "HIV infections and AIDS in the 1990s." Annual Review of Public Health 11: 127-142.

Cleland, John and Benoit Ferry. 1995. Sexual Behaviour and AIDS in the Developing World. London: Taylor and Francis.

Cleland, J., J.T. Boerma, M. Caraël, and S.S. Weir. 2004. “Monitoring sexual behaviour in general populations: A systhesis of lessons of the past decade." Sexually Transmitted Infections: 80(supplement ii): ii1-ii7.

Clumeck, Nathan, Marjorie Robert-Guroff, Philippe van de Perre, et al. 1985. "Seroepidemiological studies of HTLV-III antibody prevalence among selected groups of heterosexual Africans." Journal of the American Medical Association 254(18): 2,599-2,602.

Clumeck, N., J. Sonnet, H. Taelman, F. Mascart-Lemone, et al. 1984. "Acquired immuno-deficiency syndrome in African patients." New England Journal of Medicine 310(8): 492-497.

Coates, Thomas J., Linda Richter, and Carlos Caceres. 2008. "Behavioural strategies to reduce HIV transmission: How to make them work better." Lancet 372(9,639): 669-684.

Corbett, Elizabeth L., Richard W. Steketee, Feiko O. der Kuile, Ahmed S. Latif, Anatoli Kamali, and Richard J. Hayes. 2002. "HIV-1/ AIDS and the control of other infectious diseases in Africa." Lancet 359(9,324): 2,177-2,187.

Corey, Lawrence, Anna Wald, Connie L. Celum, and Thomas C. Quinn. 2004. "The effects of herpes simplex virus-2 on HIV-1 acquisition and transmission: A review of two overlapping epidemics." Journal of Acquired Immune Deficiency Syndromes 35(5): 435-445.

Curran, James W. 1985. "The epidemiology and prevention of the acquired immunodeficiency syndrome." Annals of Internal Medicine 103(5): 657-662

Curtis, S.L. and E.G. Sutherland. 2004. "Measuring sexual behaviour in the era of HIV / AIDS: The experience of the Demographic and Health Surveys and similar enquiries." Sexually Transmitted Infections 80(supplement ii): ii22-ii27.

Darrow, William W., Dean F. Echenberg, Harold W. Jaffe, Paul M. O'Malley, Robert H. Byers, Jane P. Getchell, and James W. Curran. 1987. "Risk factors for human immunodeficiency virus (HIV) infections in homosexual men." American Journal of Public Health 77(4): 479-483. de Bruyn, Maria. 1992. "Women and AIDS in developing countries." Social Science E Medicine 34(3): 249-262.

Decosas, J., J.K. Anarfi, K.D.R. Sodji, and H.U. Wagner. 1995. “Migration and AIDS." Lancet 346(8,978): 826-828.

Des Jarlais, Don C., Kachit Choopanya, Suphak Vanichseni, et al. 1994. "AIDS risk reduction and reduced HIV seroconversion among injection drug users in Bangkok." American Journal of Public Health 84(3): 452-455.

Des Jarlais, Don C., Samuel R. Friedman, David M. Novick, et al. 1991. "HIV-1 infection among intravenous drug users in Manhattan, New York City, from 1977 to 1987." Journal of the American Medical Association 261(7): 1,008-1,012

Des Jarlais, Don C., Samuel R. Friedman, and David Strug. 1986. “AIDS and needle sharing within the IV-drug use subculture." In The Social Dimensions of AIDS: Method and Theory. Eds. Douglas A. Feldman and Thomas A. Johnson. New York: Praeger. Pp. 111-125.

Des Jarlais, Don C., Michael Marmor, Patricia Friedmann, et al. 2000. "HIV incidence among injection drug users in New York City, 1992-1997: Evidence for a declining epidemic." American Journal of Public Health 90(3): 352-359.

DiClemente, Ralph J. and John L. Peterson. 1994. Preventing AIDS: Theories and Methods of Behavioral Interventions. New York: Plenum Press.

Dow, William H., Tomas J. Philipson, and Xavier Sala-i-Martin. 1999. "Longevity complementarities under competing risks." American Economic Review 89(5): 1,358-1,371.

Durack, David T. 1981. “Opportunistic infections and Kaposi's sarcoma in homosexual men." New England Journal of Medicine 305(24): $1,465-1,467$.

Ekstrand, Maria L. and Thomas J. Coates. 1990. "Maintenance of safer sexual behaviors and predictors of risky sex: The San Francisco Men's Health Study." American Journal of Public Health 80(8): 973-977.

Epstein, Helen. 2007. The Invisible Cure: Why We Are Losing the Fight Against AIDS in Africa. New York: Picador.

Ericksen, Karen P. and Karen F. Trocki. 1994. "Sex, alcohol and sexually transmitted diseases: A national survey." Family Planning Perspectives 26(6): 257-263.

Evans, B.A., S.G. Dawson, K.A. McLean, et al. 1986. “Sexual lifestyle and clinical findings related to HTLV-III/LAV status in homosexual men." Genitourinary Medicine 62(6): 384-389.

Fauci, Anthony S. 1982. “The syndrome of Kaposi's sarcoma and opportunistic infections: An epidemiologically restricted disorder of immunoregulation." Annals of Internal Medicine 96(6): 777-779.

Fineberg, Harvey V. 1988. "Education to prevent AIDS: Prospects and obstacles." Science 239 (4,840): 592-596.

Fishbein, Martin and Willo Pequegnat. 2000. “Evaluating AIDS prevention interventions using behavioral and biological outcome measures." Sexually Transmitted Diseases 27(2): 101-110.

Fisher, Jeffrey D. and William A. Fisher. 1992. "Changing AIDS-risk behavior." Psychological Bulletin 111(3): 455-474.

Fisher, Jeffrey D., William A. Fisher, Sunyna S. Williams, and Thomas E. Malloy. 1994. "Empirical tests of an information-motivation-behavioral skills model of AIDS-preventive behavior with gay men and heterosexual university students." Health Psychology 13(3): 238-250.

Fleming, Douglas T., Geraldine M. McQuillan, Robert E. Johnson, Andre J. Nahmias, Sevgi O. Aral, Francis K. Lee, and Michael E. St. Louis. 1997. "Herpes simplex virus type 2 in the United States, 1976 to 1994." New England Journal of Medicine 337(16): 1,105-1,111. 
Fleming, Douglas T., and Judith N. Wasserheit. 1999. "From epidemiological synergy to public health policy and practice: The contribution of other sexually transmitted diseases to sexual transmission of HIV infection." Sexually Transmitted Infections 75(1): 3-17.

Gallo, Maria F., Frieda M. Behets, Markus J. Steiner, et al. 2006. "Prostate-specific antigen to ascertain reliability of self-reported coital exposure to semen." Sexually Transmitted Diseases 33(8): 476-479.

Gallo, Robert C., Syed Z. Salahuddin, Mikulas Popovic, et al. 1984. “Frequent detection and isolation of cytopathic retroviruses (HTLV-III) from patients with AIDS and at risk for AIDS." Science 224 $(4,648)$ : 500-503.

Gallo, Robert C., Prem S. Sarin, E.P. Gelmann, et al. 1983. “Isolation of human T-cell leukemia virus in acquired immune deficiency syndrome (AIDS)." Science 220(4,599): 865-867.

Garnett, Geoffrey P. and Roy M. Anderson. 1993. "Factors controlling the spread of HIV in heterosexual communities in developing countries: Patterns of sexual mixing between different age and sexual activity classes." Philosophical Transactions of the Royal Society of London Series B 342(1,300): 137-159.

_. 1994. "Balancing sexual partnership in an age and activity stratified model of HIV transmission in heterosexual populations." Mathematical Medicine and Biology 11(3): 161-192.

Goedert, James J., M.G. Sarngadharan, Robert J. Biggar, et al. 1984. “Determinants of retrovirus (HTLV-III) antibody and immunodeficiency conditions in homosexual men." Lancet 324(8,405): 711-716.

Gottlieb, Michael S., Robert Schroff, Howard M. Schanker, et al. 1981. "Pneumocystis carinii pneumonia and mucosal candidiasis in previously healthy homosexual men." New England Journal of Medicine 305(24): 1,425-1,431.

Gray, Ronald H., Godfrey Kigozi, David Serwadda, et al. 2007. “Male circumcision for HIV prevention in men in Rakai, Uganda: A randomised trial." Lancet 369(9,562): 657-666.

Gray, Ronald H., Xiabin Li, Maria J. Wawer, et al. 2003. “Stochastic simulation of the impact of antiretroviral therapy and HIV vaccines on HIV transmission: Rakai, Uganda." AIDS 17(13): 1,941-1,951.

Gray, Ronald H., Maria J. Wawer, Ron Brookmeyer, et al. 2001. “Probability of HIV-1 transmission per coital act in monogamous, heterosexual, HIV-1-discordant couples in Rakai, Uganda." Lancet 357(9,263): 1,149-1,153.

Gregson, Simon, Geoffrey P. Garnett, Constance A. Nyamukapa, et al. 2006. "HIV decline associated with behavior change in eastern Zimbabwe." Science 311(5,761): 664-666.

Gregson, S., P. Mushati, P.J. White, M. Mlilo, C. Mundandi, and C. Nyamukapa. 2004. "Informal confidential voting interview methods and temporal changes in reported sexual risk behaviour for HIV transmission in sub-Saharan Africa." Sexually Transmitted Infections 80(supplement ii): ii36-ii42.

Grosskurth, Heiner, Frank Mosha, James Todd, et al. 1995. “Impact of improved treatment of sexually transmitted diseases on HIV infection in rural Tanzania: Randomised controlled trial." Lancet 346(8,974): 530-536

Gulick, Roy M., John W. Mellors, Diane Havlir, et al. 1997. “Treatment with indinavir, zidovudine, and lamivudine in adults with human immunodeficiency virus infection and prior antiretroviral therapy." New England Journal of Medicine 337(11): 734-739.

Gupta, Geeta R., Justin O. Parkhurst, Jessica A. Ogden, Peter Aggleton, and Ajay Mahal. 2008. "Structural approaches to HIV prevention." Lancet 372(9,640): 764-775.
Gupta, Phalguni, John Mellors, Lawrence Kingsley, Sharon Riddler, Mandaleshwar K. Singh, Susanna Schreiber, Michael Cronin, and Charles R. Rinaldo. 1997. "High viral load in semen of human immunodeficiency virus type 1-infected men at all stages of disease and its reduction by therapy with protease and nonnucleoside reverse transcriptase inhibitors." Journal of Virology 71(8): 6,271-6,275.

Gupta, Sunetra, Roy M. Anderson, and Robert M. May. 1989. “Networks of sexual contacts: Implications for the spread of HIV." AIDS 3(12): 807-817.

Halperin, Daniel T. and Robert C. Bailey. 1999. "Male circumcision and HIV infection: 10 years and counting." Lancet 354(9,192): $1,813-1,815$.

Halperin, Daniel T. and Helen Epstein. 2004. “Concurrent sexual partnerships help to explain Africa's high HIV prevalence: Implications for prevention." Lancet 364 $(9,428): 4-6$.

Hammer, Scott M., Kathleen E. Squires, Michael D. Hughes, et al. 1997. "A controlled trial of two nucleoside analogues plus indinavir in persons with human immunodeficiency virus infection and CD4 cell counts of 200 per cubic millimeter or less." New England Journal of Medicine 337(11): 725-733.

Haverkos, Harry W. and James W. Curran. 1982. “The current outbreak of Kaposi's sarcoma and opportunistic infections." CA Cancer Journal for Clinicians 32(6): 330-339.

Hayes, Richard and Helen Weiss. 2006. "Understanding HIV epidemic trends in Africa." Science 311(5,761): 620-621.

Hayes, Richard B., Susan M. Kegeles, and Thomas J. Coates. 1990. “High HIV risk-taking among young gay men." AIDS 4(9): 901-907.

Hayes, Richard, Frank Mosha, Angus Nicoll, et al. 1995. "A community trial of the impact of improved sexually transmitted disease treatment on the HIV epidemic in rural Tanzania: Design." AIDS 9(8): 919-926.

Hedlund, James. 2000. “Risky business: Safety regulations, risk compensation, and individual behavior." Injury Prevention 6(2): 82-90.

Hessol, Nancy A., Alan R. Lifson, Paul M. O'Malley, Lynda S. Doll, Harold W. Jaffe, and George W. Rutherford. 1989. “Prevalence, incidence, and progression of human immunodeficiency virus infection in homosexual and bisexual men in hepatitis B vaccine trials, 1978-1988." American Journal of Epidemiology 130(6): 1,167-1,175.

Hethcote, Herbert W. 1976. “Qualitative analysis of communicable disease models." Mathematical Biosciences 28: 335-356.

Hethcote, Herbert W. and James W. van Ark. 1992. Modeling HIV transmission and AIDS in the United States. Lecture Notes in Biomathematics, volume 95. New York: Springer-Verlag.

Holtzman, Deborah, Shayne D. Bland, Amy Lansky, and Karin A. Mack. 2001. "HIV-related behaviors and perceptions among adults in 25 states: 1997 Behavioral Risk Factor Surveillance System." American Journal of Public Health 91(11): 1,882-1,888.

Hoover, Donald R., Alvaro Munoz, Vincent Carey, et al. 1991. “Estimating the 1978-1990 and future spread of human immunodeficiency virus type 1 in subgroups of homosexual men." American Journal of Epidemiology 134(10): 1,190-1,205.

Hrdy, Daniel B. 1987. "Cultural practices contributing to the transmission of human immunodeficiency virus in Africa." Review of Infectious Diseases 9(6): 1,109-1,119.

Hunter, David J. 1993. “AIDS in sub-Saharan Africa: The epidemiology of heterosexual transmission and prospects for prevention." Epidemiology 4(1): 63-72. 
Jacquez, John A., James S. Koopman, Carl P. Simon, and Ira M. Longini. 1994. "Role of the primary infection in epidemics of HIV infection in gay cohorts." Journal of Acquired Immune Deficiency Syndromes 7(11): 1,169-1,184.

Jacquez, John A., Carl P. Simon, James Koopman, Lisa Sattenspiel, and Timothy Perry. 1988. "Modeling and analyzing HIV transmission: The effect of contact patterns." Mathematical Biosciences 92(2) 119-199.

Jaffe, Harold W., Dennis J. Bregman, and Richard M. Selik. 1983a. “Acquired immune deficiency syndrome in the United States: The first 1,000 cases." Journal of Infectious Diseases 148(2): 339-345.

Jaffe, Harold W., Keewhan Choi, Pauline A. Thomas, et al. 1983b. “National case-control study of Kaposi's sarcoma and Pneumocystic carinii pneumonia in homosexual men: Part 1, Epidemiologic results." Annals of Internal Medicine 99(2): 145-151.

Jaffe, Harold W., William W. Darrow, Dean F. Echenberg, et al. 1985. "The acquired immunodeficiency syndrome in a cohort of homosexual men: A six-year follow-up study." Annals of Internal Medicine 103(2): 210-214.

Jemmott, John B., Loretta S. Jemmott, and Geoffrey T. Fong. 1992. “Reductions in HIV risk-associated sexual behaviors among black male adolescents: Effects of an AIDS prevention intervention." American Journal of Public Health 82(3): 372-377.

Jochelson, Karen, Monyaola Mothibeli, and Jean-Patrick Leger. 1991. "Human immunodeficiency virus and migrant labor in South Africa." International Journal of Health Services 21(1): 157-173.

Johnson, Anne M. 1988. "Heterosexual transmission of human immunodeficiency virus." British Medical Journal 296(6,628): 1,0171,020 .

Johnson, Anne M. and Marie Laga. 1988. “Heterosexual transmission of HIV." AIDS 2(supplement 1): s49-s56.

Judson, Franklyn N. 1983. "Fear of AIDS and gonorrhea rates in homosexual men." Lancet 2(8,342): 159-160.

Kamali, A., M. Quigley, J. Nakiyingi, et al. 2003. “Syndromic management of sexually-transmitted infections and behaviour change interventions on transmission of HIV-1 in rural Uganda: A community randomised trial." Lancet 361(9,358): 645-652.

Karon, John M., Patricia L. Fleming, Richard W. Steketee, and Kevin M. De Cock. 2001. "HIV in the United States at the turn of the century: An epidemic in transition." American Journal of Public Health 91(7): $1,060-1,068$.

Kaslow, Richard A., Tevfik Dorak, and James Tang. 2005. "Influence of host genetic variation on susceptibility to HIV Type 1 infection." Journal of Infectious Diseases 191(supplement 1): s68-s77.

Kelly, Jeffrey A., Janet S. St. Lawrence, Yolanda E. Diaz, et al. 1991. “HIV risk behavior reduction following intervention with key opinion leaders in population: An experimental analysis." American Journal of Public Health 81(2): 168-171.

Kermack, W.O. and A.G. McKendrick. 1927. "A contribution to the mathematical theory of epidemics." Proceedings of the Royal Society of London Series A 115(772): 700-721.

Killian, Albert H.D., Simon Gregson, Bannet Ndyanabangi, et al. 1999. "Reductions in risk behaviour provide the most consistent explanation for declining HIV-1 prevalence in Uganda." AIDS 13(3): 391-398.

Kingsley, Lawrence A., Roger Detels, Richard Kaslow, et al. 1987. “Risk factors for seroconversion to human immunodeficiency virus among male homosexuals." Lancet 329(8,529): 345-348.
Kipke, Michael D., Cherrie Boyer, and Karen Hein. 1993. “An evaluation of an AIDS risk reduction education and skills training (ARREST) program." Journal of Adolescent Health 14(7): 533-539.

Koopman, James S., John A. Jacquez, Gavin W. Welch, et al. 1997. “The role of early HIV infection in the spread of HIV through populations." Journal of Acquired Immune Deficiency Syndromes and Human Retrovirology 14(3): 249-258.

Koopman, James, Carl Simon, C., John Jacquez, Jill Joseph, Lisa Sattenspiel, and Taesung Park. 1988. "Sexual partner selectiveness effects on homosexual HIV transmission dynamics." Journal of Acquired Immune Deficiency Syndromes 1(5): 486-504.

Korenromp, Eline L., Carina Van Vliet, Heiner Grosskurth, et al. 2000. "Model-based evaluation of single-round mass treatment of sexually transmitted diseases for HIV control in a rural African population." AIDS 14(5): 573-593.

Kreiss, Joan K. and Sharon G. Hopkins. 1993. "The association between circumcision status and human immunodeficiency virus infection among homosexual men." Journal of Infectious Diseases 168(6): $1,404-1,408$

Kreiss, Joan K., Lynn W. Kitchen, Harry E. Prince, Carol K. Kasper, and Max Essex. 1985. "Antibody to human T-lymphotropic virus type III in wives of hemophiliacs: Evidence of heterosexual transmission." Annals of Internal Medicine 102(5): 623-626.

Kremer, Michael. 1996. "Integrating behavioral choice into epidemiological models of AIDS." Quarterly Journal of Economics 111(2): 549-573.

Kremer, Michael and Charles Morcom. 1998. “The effect of changing sexual activity on HIV prevalence." Mathematical Biosciences 151(1): 99-122.

Kretzschmar, Mirjam and Martina Morris. 1996. "Measures of concurrency in networks and the spread of infectious disease." Mathematical Biosciences 133(2): 165-195.

$\mathrm{Ku}$, Leighton, Michael St. Louis, Carol Farshy, Sevgi Aral, Charles F. Turner, Laura D. Lindberg, and Freya Sonenstein. 2002. "Risk behaviors, medical care, and chlamydial infection among young men in the United States." American Journal of Public Health 92(7): 1,140-1,143.

Ku, Leighton, Freya L. Sonenstein, Laura D. Lindberg, Carolyn H. Bradner, Scott Boggess, and Joseph H. Pleck. 1998. "Understanding changes in sexual activity among young metropolitan men: 1979-1995." Family Planning Perspectives 30(6): 256-262.

Lagarde, Emmanuel, Bertran Auvert, Michel Caraël, et al. 2001. “Concurrent sexual partnerships and HIV prevalence in five urban communities in sub-Saharan Africa." AIDS 15(7): 877-884.

Larson, Ann. 1989. "Social context of human immunodeficiency virus transmission in Africa: Historical and cultural bases of East and Central African sexual relations." Review of Infectious Diseases 11(5): 716-731.

Laumann, Edward O., Christopher M. Masi, and Ezra W. Zuckerman. 1997. "Circumcision in the United States: Prevalence, prophylactic effects, and sexual practice." Journal of the American Medical Association 277(13): 1,052-1,057.

Laumann, Edward O., Robert T. Michael, and Gina Kolata. 1994. Sex in America: A Definitive Survey. Boston: Little, Brown.

Lavreys, Ludo, Joel P. Rakwar, Mary Lou Thompson, et al. 1999. “Effect of circumcision on incidence of human immunodeficiency virus type 1 and other sexually transmitted diseases: A prospective cohort study of trucking company employees in Kenya." Journal of Infectious Diseases 180(2): 330-336. 
Law, Matthew G., Garrett Prestage, Andrew Grulich, Paul Van de Ven, and Susan Kippax. 2001. "Modelling the effect of combination antiretroviral treatments on HIV incidence." AIDS 15(10): 1,287-1,294.

Le Blanc, Marie-Nathalie, Deirdre Meintel, and Victor Piché. 1991. “The African sexual system: Comment on Caldwell et al." Population and Development Review 17(3): 497-505.

Leigh, Barbara C., Mark T. Temple, and Karen F. Trocki. 1993. “The sexual behavior of US adults: Results from a national survey." American Journal of Public Health 83(10): 1,400-1,408.

Lurie, Peter, Percy Hintzen, and Robert A. Lowe. 1995. “Socioeconomic obstacles to HIV prevention and treatment in developing countries: The roles of the International Monetary Fund and the World Bank." AIDS 9(6): 539-546.

Macintyre, Kate, Lisanne Brown, and Stephen Sosler. 2001. “It's not what you know, but who you know: Examining the relationship between behavior change and AIDS mortality in Africa." AIDS Educatoin and Prevention 13(2): 160-174.

Malamba, Samuel S., Hans-Ulrich Wagner, Gillian Maude, Martin Okongo, Andrew J. Nunn, Jane F. Kengeya-Kayondo, and Dean W. Mulder. 1994. "Risk factors for HIV-1 infection in adults in a rural Ugandan community: A case-control study." AIDS 8(2): 253-257.

Manhart, Lisa E., Sevgi O. Aral, King K. Holmes, and Betsy Foxman. 2002. "Sex partner concurrency: Measurement, prevalence, and correlates among urban 18-39-year-olds." Sexually Transmitted Diseases 29(3): 133-143.

Martin, John L. 1987. "The impact of AIDS on gay male sexual behavior patterns in New York City." American Journal of Public Health 77(5): 578-581.

Masur, Henry, Mary Ann Michelis, Jeffrey B. Greene, et al. 1981. “An outbreak of community-acquired Pneumocystis carinii pneumonia: Initial manifestation of cellular immune dysfunction." New England Journal of Medicine 305(24): 1,431-1,438.

May, Robert M. and Roy M. Anderson. 1987. “Transmission dynamics of HIV infection." Nature 326(6,109): 137-142.

Mayer, Kenneth H., David Ayotte, Jerome E. Groopman, Anne M. Stoddard, Mangalasseril Sarngadharan, and Robert Gallo. 1986. “Association of human T-lymphotropic virus type III antibodies with sexual and other behaviors in a cohort of homosexual men from Boston with and without generalized lymphadenopathy." American Journal of Medicine 80(3): 357-363.

McKusick, Leon, William Horstman, and Thomas J. Coates. 1985a. "AIDS and sexual behavior reported by gay men in San Francisco." American Journal of Public Health 75(5): 493-496.

McKusick, Leon, James A. Wiley, Thomas J. Coates, et al. 1985b. “Reported changes in the sexual behavior of men at risk for AIDS, San Francisco, 1982-84: The AIDS Behavioral Research Project." Public Health Reports 100(6): 622-629.

McQuillan, Geraldine M., Deanna Kruszon-Moran, Benny J. Kottiri, et al. 2006. "Prevalence of HIV in the US household population: The National Health and Nutrition Examination Surveys, 1988 to 2002." Journal of Acquired Immune Deficiency Syndromes 41(5): 651-656.

Mehryar, Amir. 1995. "Condoms: Awareness, attitudes, and use." In Sexual Behaviour and AIDS in the Developing World. Eds. John Cleland and Benoît Ferry. London: Taylor and Francis. Pp. 124-156.

Melbye, Mads, Robert J. Biggar, Peter Ebbesen, M.G. Sarngadharan, Stanley H. Weiss, Robert C. Gallo, and William A. Blattner. 1984. "Seroepidemiology of HTLV-III antibody in Danish homosexual men: Prevalence, transmission, and disease outcome." British Medical Journal 289(6,445): 573-575.
Mensch, Barbara S., Paul C. Hewett, and Annabel Erulkar. 2003. “The reporting of sensitive behavior by adolescents: A methodological experiment in Kenya." Demography 40(2): 247-268.

Merson, Michael H., Jeffrey O'Malley, David Serwadda, and Chantawipa Apisuk. 2008. "The history and challenge of HIV prevention." Lancet 372(9,637): 475-488.

Miller, Norman and Richard C. Rockwell. 1988. AIDS in Africa: The Social and Policy Impact. Lewiston, NY: Edwin Mellen Press.

Millett, Gregorio A., John L. Peterson, Richard J. Wolitski, and Ron Stall. 2006. "Greater risk of HIV infection in black men who have sex with men: A critical literature review." American Journal of Public Health 96(6): 1,007-1,019.

Morris, Martina, Mark S. Handcock, William C. Miller, et al. 2006. "Prevalence of HIV infection among young adults in the United States: Results from the Add Health study." American Journal of Public Health 96(6): 1,091-1,097.

Morris, Martina and Mirjam Kretzschmar. 1995. “Concurrent partnerships and transmission dynamics in networks." Social Networks 17(3-4): 299-318.

- 1997. "Concurrent partnerships and the spread of HIV." AIDS 11(5): 641-648.

Moses, Stephen, Robert C. Bailey, and Allan R. Ronald. 1998. "Male circumcision: Assessment of health benefits and risks." Sexually Transmitted Infections 74(5): 368-373.

Moses, Stephen, Janet E. Bradley, Nico J.D. Nagelkerke, Allan R. Ronald, J.O. Ndinya-Achola, and Francis A. Plummer. 1990. “Geographical patterns of male circumcision practices in Africa: Association with HIV seroprevalence." International Journal of Epidemiology 19(3): 693-697.

Moss, Andrew R., Dennis Osmond, Peter Bacchetti, Jean-Claude Chermann, Françoise Barré-Sinoussi, and James Carlson. 1987. “Risk factors for AIDS and HIV seropositivity in homosexual men." American Journal of Epidemiology 125(6): 1,035-1,047.

Muntaner, Julio S.G., Robert Hogg, Evan Wood, Thomas Kerr, Mark Tyndall, Adrian R. Levy, and P. Richard Harrigan. 2006. “The case for expanding access to highly active antiretroviral therapy to curb the growth of the HIV epidemic." Lancet 368(9,534): 531-536.

Nagelkerke, Nico J.D., Prabhat Jha, Sake J. de Vlas, Eline L. Korenromp, Stephen Moses, James F. Blanchard, and Frank A. Plummer. 2002. "Modelling the HIV / AIDS epidemics in Botswana and India: Impact of interventions to prevent transmission." Bulletin of the World Health Organization 80(2): 89-96.

Nakashima, Allyn K., Robert T. Rolfs, Melinda L. Flock, Peter Kilmarx, and Joel R. Greenspan. 1996. "Epidemiology of syphilis in the United States, 1941-1993." Sexually Transmitted Diseases 23(1): 16-23.

Nelson, Kenrad E., David D. Celentano, Sakol Eiumtrakol, et al. 1996. "Changes in sexual behavior and a decline in HIV among young men in Thailand." New England Journal of Medicine 335(5): 297-303.

Nicholson, Janet K.A., Steven McDougal, Harold W. Jaffe, et al. 1985. "Exposure to human T-lymphotropic virus type III/lymphadenopathy-associated virus and immunologic abnormalities in asymptomatic homosexual men." Annals of Internal Medicine 103(1): 37-42.

O'Farrell, Nigel and Matthias Egger. 2000. "Circumcision in men and the prevention of HIV infection: A 'meta-analysis' revisited." International Journal of STD and AIDS 11(3): 137-142.

Osoba, A.O. 1981. "Sexually transmitted diseases in tropical Africa: A review of the present situation." British Journal of Venereal Diseases 57(2): 89-94. 
Padian, Nancy S. 1987. “Heterosexual transmission of acquired immunodeficiency syndrome: International perspectives and national projections." Review of Infectious Diseases 9(5): 947-960.

Padian, Nancy S., Anne Buvé, Jennifer Balkus, David Serwadda, and Ward Cates. 2008. "Biomedical interventions to prevent HIV infection: Evidence, challenges, and way forward." Lancet 372(9,638): 585-599.

Penkower, Lili, Mary A. Dew, Lawrence Kingsley, James T. Becker, Paul Satz, Frederick W. Schaerf, and Kathleen Sheridan. 1991. “Behavioral, health and psychosocial factors and risk for HIV infection among sexually active homosexual men: The Multicenter AIDS Cohort Study." American Journal of Public Health 81(2): 194-196.

Perkins, Diana O., Jane Leserman, Carol Murphy, and Dwight L. Evans. 1993. "Psychosocial predictors of high-risk sexual behavior among HIV-negative homosexual men." AIDS Education and Prevention 5(2): 141-152.

Peters, Andy D., Margaret M. Reid, and Shay G. Griffin. 1994. “Edinburgh drug users: Are they injecting and sharing less?" AIDS 8(4): 521-528.

Peterson, John L., Thomas J. Coates, Joseph A. Catania, Lee Middleton, Bobby Hilliard, and Norman Hearst. 1992. "High-risk sexual behavior and condom use among gay and bisexual African-American men." American Journal of Public Health 82(11): 1,490-1,494.

Piot, Peter, Michael Bartos, Heidi Larson, Debrework Zewdie, and Purnima Mane. 2008. "Coming to terms with complexity: A call to action for HIV prevention." Lancet 372(9,641): 845-959.

Piot, Peter, Francis A. Plummer, Fred S. Mhalu, Jean-Louis Lamboray, James Chin, and Jonathan M. Mann. 1988. “AIDS: An international perspective." Science 239(4,840): 573-579.

Piot, Peter, Thomas C. Quinn, Henri Taelman, et al. 1984. "Acquired immunodeficiency syndrome in a heterosexual population in Zaire." Lancet 324(8,394): 65-69.

Plummer, M.L., D.A. Ross, D. Wight, et al. 2004. “A bit more truthful: The validity of adolescent sexual behaviour data collected in rural Tanzania using five methods." Sexually Transmitted Infections 80(supplement ii): ii49-ii56.

Quigley, Maria, Katua Munguti, Heiner Grosskurth, et al. 1997. “Sexual behaviour patterns and other risk factors for HIV infection in rural Tanzania: A case-control study." AIDS 11(2): 237-248.

Quinn, Thomas C., Jonathan M. Mann, James W. Curran, and Peter Piot. 1986. "AIDS in Africa: An epidemiologic paradigm." Science 234(4,779): 955-963.

Quinn, Thomas C., Peter Piot, Joseph B. McCormick, et al. 1987. “Serologic and immunologic studies in patients with AIDS in North America and Africa: The potential role of infectious agents as cofactors in human immunodeficiency virus infection." Journal of the American Medical Association 257(19): 2,617-2,621.

Quinn, Thomas C., Maria J. Wawer, Nelson Sewankambo, et al. 2000. "Viral load and heterosexual transmission of human immunodeficiency virus type 1." New England Journal of Medicine 342(13): 921-929.

Rickert, Vaughn I., Anita Gottlieb, and M. Susan Jay. 1990. “A comparison of three clinic-based AIDS education programs on female adolescents' knowledge, attitudes, and behavior." Journal of Adolescent Health Care 11(4): 298-303.

Robinson, N. Jamie, Daan W. Mulder, Bertran Auvert, and Richard J. Hayes. 1995. "Modelling the impact of alternative HIV intervention strategies in rural Uganda." AIDS 9(11): 1,263-1,270.
Sanders, David and Abdulraham Sambo. 1991. "AIDS in Africa: The implications of economic recession and structural adjustment." Health Policy and Planning 6(2): 157-165.

Sarngadharan, M.G., Mikulas Popovic, Lilian Bruch, Jörg Schüpbach, and Robert C. Gallo. 1984. "Antibodies reactive with human Tlymphotropic retroviruses (HTLV-III) in the serum of patients with AIDS." Science 224(4,648): 506-508.

Schechter, Martin T., William K. Boyko, Bruce Douglas, et al. 1986. “The Vancouver Lymphadenopathy-AIDS Study: 6. HIV seroconversion in a cohort of homosexual men." Canadian Medical Association Journal 135(12): 1,355-1,360.

Schoenbaum, Ellie E., Diana Hartel, Peter A. Selwyn, et al. 1989. “Risk factors for human immunodeficiency virus infection in intravenous drug users." New England Journal of Medicine 321(13): 874-879.

Schoepf, Brooke G. 1988. "Women, AIDS, and economic crisis in Central Africa." Canadian Journal of African Studies 22(3): 625-644.

. 1993. "Gender, development, and AIDS: A political economy and culture framework." In Women and International Development. Eds. R. Gallin, A. Ferguson, and J. Harper. Boulder, CO: Westview Press. Pp. 53-85.

Schoub, B.D., A. Smith, S. Lyons, S. Johnson, D. Martin, G. McGillivray, G. Padayachee, S. Naidoo, E. Fisher, and H. Hurwitz. 1988. “Epidemiological considerations of the present status and future growth of the AIDS epidemic in South Africa." South African Medical Journal 74(2): 153-157.

Seed, Jeff, Susan Allen, Thierry Mertens, et al. 1995. "Male circumcision, sexually transmitted disease, and risk of HIV." Journal of Acquired Immune Deficiency Syndromes and Human Retrovirology 8(1): 83-90.

Siegal, Frederick P., Carlos Lopez, Glenn S. Hammer, et al. 1981. “Severe acquired immunodeficiency in male homosexuals, manifested by chronic perianal ulcerative herpes simplex lesions." New England Journal of Medicine 305(24): 1,439-1,444.

Simpson, D. Dwayne, Kevin Knight, and Scott Ray. 1993. "Psychosocial correlates of AIDS-risk drug use and sexual behaviors." AIDS Education and Prevention 5(2): 121-130.

Smith, Dawn K., Marta Gwinn, Richard M. Selik, et al. 2000. “HIV/ AIDS among African Americans: Progress or progression?" AIDS 14(9): 1,237-1,248.

Smith, Kristen P. and Susan C. Watkins. 2005. "Perceptions of risk and strategies for prevention: Responses to HIV / AIDS in rural Malawi." Social Science \& Medicine 60(3): 649-660.

Sonenstein, Freya L., Leighton Ku, Laura D. Lindberg, Charles F. Turner, and Joseph H. Pleck. 1998. "Changes in sexual behavior and condom use among teenaged males: 1988 to 1995." American Journal of Public Health 88(6): 956-959.

Sonenstein, Freya L., Joseph H. Pleck, and Leighton C. Ku. 1989. "Sexual activity, condom use and AIDS awareness among adolescent males." Family Planning Perspectives 21(4): 152-158.

St. Lawrence, Janet S., Ted L. Brasfield, Kennis W. Jefferson, Edna Alleyne, Robert E. O'Brannon, and Aaron Shirley. 1995. “Cognitivebehavioral intervention to reduce African American adolescents' risk for HIV infection." Journal of Consulting and Clinical Psychology 63(2): 221-237.

Stokes, Joseph P. and John L. Peterson. 1998. "Homophobia, self-esteem, and risk for HIV among African American men who have sex with men." AIDS Education and Prevention 10(3): 278-292.

Stoneburner, Rand L. and Daniel Low-Beer. 2004. "Population-level HIV declines and behavioral risk avoidance in Uganda." Science 304(5,671): 714-718. 
Strecher, Victor J. and Irwin M. Rosenstock. 1997. "The Health Belief Model." In Health Behavior and Health Education: Theory, Research, and Practice. Eds. Karen Glanz, Frances M. Lewis, and Barbara K. Rimer. San Francisco: Jossey-Bass. Pp. 41-59.

Sumartojo, Esther. 2000. "Structural factors in HIV prevention: Concepts, examples, and implications for research." AIDS 14(supplement 1): s3-s10.

Tanfer, Koray, William R. Grady, Daniel H. Klepinger, and John O.G. Billy. 1993. “Condom use among U.S. men, 1991." Family Planning Perspectives 25(2): 61-66.

Tawil, Oussama, Annette Verster, and Kevin R. O'Reilly. 1995. “Enabling approaches for HIV / AIDS prevention: Can we modify the environment and minimize the risk?" AIDS 9(12): 1,299-1,306

Taylor, Shelley E., Margaret E. Kemeny, Lisa G. Aspinwall, Stephen G. Schneider, Richard Rodriguez, and Mark Herbert. 1992. “Optimism, coping, psychological distress, and high-risk sexual behavior among men at risk for acquired immunodeficiency syndrome (AIDS)." Journal of Personality and Social Psychology. 63(3): 460-473.

Ulin, Priscilla R. 1992. "African women and AIDS: Negotiating behavioral change." Social Science \& Medicine 34(1): 63-73.

UNAIDS. 2007. New Data on Male Circumcision and HIV Prevention: Policy and Programme Implications (WHO/UNAIDS Technical Consultation). Geneva: UNAIDS.

. 2008. 2008 Report on the Global AIDS Epidemic. Geneva: UNAIDS.

Urassa, Marc, James Todd, J. Ties Boerma, Richard Hayes, and Raphael Isingo. 1997. "Male circumcision and susceptibility to HIV infection among men in Tanzania." AIDS 11(1): 73-80.

Valdiserri, Ronald O. 1989. Preventing AIDS: The Design of Effective Programs. New Brunswick, NJ: Rutgers University Press.

Van de Perre, Philippe, Dominique Rouvroy, Philippe Lepage, et al. 1984. "Acquired immunodeficiency syndrome in Rwanda." Lancet 324(8,394): 62-65.

van Griensven, Godfried J.P., Nancy A. Hessol, Veryl A. Koblin, et al. 1993. "Epidemiology of human immunodeficiency virus type 1 infection among homosexual men participating in hepatitis B vaccine trials in Amsterdam, New York City, and San Francisco, 19781990." American Journal of Epidemiology 137(8): 909-915.

Vernazza, Pietro L., Bruce L. Gilliam, John Dyer, Susan A. Fiscus, Joseph J. Eron, Andreas C. Frank, and Myron S. Cohen. 1997. "Quantification of HIV in semen: Correlation with antiviral treatment and immune status." AIDS 11(8): 987-993.

Vlahov, David, Alvaro Muñoz, James C. Anthony, Sylvia Cohn, David D. Celentano, and Kenard E. Nelson. 1990. "Association of drug injection patterns with antibody to human immunodeficiency virus type 1 among intravenous drug users in Baltimore, Maryland." American Journal of Epidemiology 132(5): 847-856.

Wald, Anna. 2004. "Synergistic interactions between herpes simplex virus type-2 and human immunodeficiency virus epidemics." Herpes 11(3): 70-76.

Wasserheit, Judith N. 1992. “Epidemiological synergy: Interrelationships between human immunodeficiency virus infection and other sexually transmitted diseases." Sexually Transmitted Diseases 19(2): 61-77.

Watkins, Susan C. 2004. "Navigating the AIDS epidemic in rural Malawi." Population and Development Review 30(4): 673-705.
Watts, Charlotte H. and Robert M. May. 1992. "The influence of concurrent partnerships on the dynamics of HIV/AIDS." Mathematical Biosciences 108(1): 89-104.

Wawer, Maria J., Nelson K. Sewankambo, David Serwadda, et al. 1999. "Control of sexually transmitted diseases for AIDS prevention in Uganda: A randomised community trial." Lancet 353(9,152): 525-535.

Weber, J.N., A. McCreaner, E. Berrie, J. Wadsworth, D.J. Jeffries, A.J. Pinching, and J.R.W. Harris. 1986. “Factors affecting seropositivity to human T-cell lymphotropic virus type III (HTLV-III) or lymphadenopathy associated virus (LAV) and progression of disease in sexual partners of patients with AIDS." Genitourinary Medicine 62(3): 177-180.

Weiss, Helen A., Maria A. Quigley, and Richard J. Hayes. 2000. “Male circumcision and risk of HIV infection in sub-Saharan Africa: A systematic review and meta-analysis." AIDS 14(15): 2,361-2,370.

Weller, I.V.D., D.J. Hindley, M.W. Adler, and J.T. Meldrum. 1984. “Gonorrhea in homosexual men and media coverage of the acquired immune deficiency syndrome in London, 1982-3." British Medical Journal 289(6,451): 1,041.

William, Daniel C. 1984. “The prevention of AIDS by modifying sexual behavior." Annals of the New York Academy of Sciences 437: 283-285.

Williams, Brian G. and Eleanor Gouws. 2001. “The epidemiology of human immunodeficiency virus in South Africa." Philosophical Transactions of the Royal Society of London Series B 356(1,411): 1,077-1,086.

Williams, Brian G., James O. Lloyd-Smith, Eleanor Gouws, et al. 2006. "The potential impact of male circumcision on HIV in sub-Saharan Africa." PLoS Medicine 3(7): 1,032-1,040.

Winkelstein, Warren, David M. Lyman, Nancy Padian, et al. 1987. “Sexual practicies and risk of infection by the human immunodeficiency virus: The San Francisco Men's Health Study." Journal of the American Medical Association 257(3): 321-325.

World Bank. 1997. Confronting AIDS: Public Priorities in a Global Epidemic. New York: Oxford University Press.

Zwi, Anthony and Deborah Bachmayer. 1990. "HIV and AIDS in South Africa: What is an appropriate public health response?" Health Policy and Planning 5(4): 316-326.

Zwi, Anthony B. and Antonio J. R. Cabral. 1991. “Identifying ‘high risk situations' for preventing AIDS." British Medical Journal 303(6,816): $1,527-1,529$.

\section{Acknowledgments}

This research was supported by an NIA grant to the Michigan Center on the Demography of Aging, a grant from the Eunice Kennedy Shriver National Institute of Child Health and Human Development to the Population Research Institute at Pennsylvania State University, a fellowship to Arline T. Geronimus from the Center for Advanced Study in the Behavioral Sciences at Stanford University, and the Robert Wood Johnson Health and Society Scholars Program at the Harvard School of Public Health. We thank John Bound, Stephen Raudenbush, Carl Simon, and Rachael Snow for thoughtful feedback on earlier versions of this study. 